\title{
Editorial:
}

\section{Disaster Medicine: Future Challenges}

In the last ten years, we have witnessed an increasing number of manmade and natural disasters which have critically challenged preparedness for such events and the quality of medical responses to cope with them. Too frequently, in the analysis of the causes of these disasters, it has become evident that they were predictable and preventable. It is predictable that thousands of children will perish in famine when there is inadequate transportation for their food. It is predictable that aging aircraft will collapse when maintenance is neglected, and its is painfully predictable that when a mass of spectators gathers for pleasure, disasters can happen without warning, but never without possibility. The challenge is to intelligently predict, to prevent, and to minimize the consequences of all disasters. Perhaps we have erred in attempting to "harden the target"- to accept that there will always be disasters and to strive to find a means to lessen injury and hasten repair. Compulsory wearing of seat belts, the wearing of hard hats by cyclists, the elimination of solid barriers for crowd control in soccer stadiums are well-known examples of hardening the target. Accidents always will occur but they need not be so traumatic. Road accidents no longer are a preventable health disorder only in developed countries. They are increasingly a major health problem in developing countries. It remains an ongoing challenge for governments to accept that, in terms of productive years of life lost, the carnage from traffic accidents is greater than the total years of life lost from coronary disease and cancer. In planning for safer cities of the future, governments also must recognize that by the turn of the century, all countries will have a greater proportion of elderly citizens at risk from both pedestrian accidents and from their inability to cope with faster cars and the increasing sophistication of electronic gadgetry.

The World Association of Emergency and Disaster Medicine gathers from some fifty countries experts in the job of delivering emergency care, disaster planning and management. It has been fortunate from the early days of its foundation-originally as a brainchild of the late Rudolf Frey and Peter Safar, and known then as the Club of Mainz-to have attracted physicians and health workers who had front-line experience in dealing with disasters. The concerns of the Association focus on problems of wide and important interest including famines, terrorism, aircraft crashes, water rescue, chemical, and nuclear disasters. Perhaps the greatest challenge to improve the quality of medical response to disasters worldwide, is to question the standards of teaching emergency and disaster medicine at both undergraduate and postgraduate levels in all medical schools. For many, this is a neglected topic.

Disaster planning is effective only when the lessons of disaster management and mismanagement are analyzed critically. Sharing of knowledge among nations in techniques of delivering immediate aid and resuscitation, and the willingness to help neighboring countries when their resources can no longer cope are challenges now being met and encouraged by WAEDM.

In September the 6th World Congress on Emergency and Disaster Medicine to be held in Hong Kong will draw together health professionals from many disciplines and many countries who are willing to share, teach, learn, and help harden the target for greater survival.

Morgan Fahey, OBE, MBChB (NZ), FRNZCG

President, The World Association for Emergency and Disaster Medicine 